\title{
Digitizing Art or How to Broaden the Viewer's Experience
}

\author{
Alexandra Orlova \\ Russian State Art Library \\ Moscow, Russia \\ aocifra@gmail.com
}

\begin{abstract}
As all of us, know 2020 gave a new meaning to the phrase "Go fully digital". For many institutions, this new era of online entertainment became a true challenge. If earlier digital art was an experimental practice, which not everyone wanted to understand, in today's situation it became an impossible opinion due to the fact that all of us did our best to master the digital sphere while working from home. The paper seeks to demonstrate how digital documentation and digital exhibitions became an important part of contemporary exhibition life. Through different examples of video, media, and other types of "digitized" art the author will show digital exhibits may create a place where all viewers are able to come from any location in the world. The main focus of the paper is a case study of three digital exhibitions - two made at the Russian State Art Library as a part of the "RSAL Studio" program, one made by students of the first Russian Digital Art MA program "-Da. Digital Art". Each exhibit has a different approach to the concept of demonstration of art and methods of its creation. The paper will be followed by an image demonstration, which the author will prepare in case of the proposal approval.
\end{abstract}

Digital. Challenge. Online. Exhibition. Demonstration. Contemporary art.

\section{INTRODUCTION}

From the moment computer became an unavoidable component of our life, artists strive to broaden the features it can offer them. During the years, artists had experimented with Internet. We saw projects that allowed people to grow a public garden by just accessing their personal computers, or read letters that load slowly due to the Internet speed at the moment. All of that created a unique space of digital art where traditional or non-digital colleagues were not able to exist for a while.

All of it ended with social media invasion that created a situation where you and your art does not exist if you forgot to set up a Facebook / Instagram / Vimeo / Youtube page, or just a personal website. With these instruments art became a bit closer to the viewer. It became easier to avoid galleries and art dealers by just following your favourite artist on Instagram. Of course, a picture of a painting can never be compared with a digital algorithm, which was specially designed for the computer or for a media installation.

The situation became more peculiar in 2020 when all of us who preferred offline activities were forced to go digital. In fact, it was a kind of a dare not only for artists, but also for the curators whose work is to connect the spectator with a piece of art. In my personal experience it was an interesting opportunity that taught my colleagues and me a lesson on how to document, preserve and present art in the conditions of the brave new world.

For me this text is an observation of an art curator in the conditions all art workers were put during the pandemic we are still facing. Examples I chose reflect how some art institutions had to become flexible in a glimpse and how digital artists benefited from the whole situation.

\section{DIGITIZING AS THE NEW TRUTH}

\subsection{Atmosphere as a basic category of contemporary art}

It is out of question that every person who works in the sphere of contemporary art read Walter Benjamin's essay "The Work of Art in the Age of Mechanical Reproduction". From there we know that Benjamin thought that even an outskirt theatre production of a renowned play would be better than a film, because a film has no aura. The same approach he applied to arts that can be multiplied, 
like printed art and photography. But the fact is that if we break a lithography stone or destroy a negative there would be nothing to recreate. This way the artist can stop the amount of his / her artwork edition. Same can be said about media and digital art - as soon as the artist deletes the file after making some copies or screenshots of a webpage there would be nothing left to multiply.

But what about aura? Benjamin says there is none in such kind of works. He says: "Even the most perfect reproduction of a work of art is lacking in one element: its presence in time and space, its unique existence at the place where it happens to be" (Benjamin 2007). According to this statement, media art cannot be included into this elite aura world, which is very arguable.

For this matter another category was developed by a German philosopher Gernot Böhme, he named it atmosphere (Böhme 1993). This category can be applied to any type of art without any judgement of the medium it was made in. This way atmosphere analyses the environment an art piece creates in an exhibition space. "With multimedia installations there is a full affirmation of the idea of the workcum-environment, a work that envelops the viewer. Thus we react to these installations as though reacting to an environment into which we enter" (Tavani 2018). This example highlights the fact that today we need new categories to speak about art because now it is not only sculpture and painting, but also so much more.

Of course, this rule can be easily applied to a traditional exhibition space that we enter in a gallery or a museum. There we have all the important components: space, art, spectator, but as we all know the rules may change.

\subsection{The 2020 transition}

It is out of mentioning that 2020 became a shock to all exhibition curators. Literally, in a second all of us were forced to reinvent how we demonstrate art. For those who constantly work with media and digital artists it was not a very hard job, but for those who are used to create mixed exhibitions it was quite a challenge.

First of all, we don't see a physical spectator in the Internet, so this category becomes very abstract. Yes, an exhibition web-site gives us the numbers of clicks and views, but who were these people, how did they like the show, which work caught their eye the moment they've went to the online galley we do not know. That leads to a crisis that I would like to name as the spectatorship crisis and it cannot be solved by numerous online lectures and Zoom meetings in a short time period. But we will need to learn to cope with it.
To trace how the spectator's category became more and more abstract I would like to overview three exhibitions. Two of them I had a chance to curate myself, one of the third one seems the possible future of digital curation and art observation for me.

\subsection{No pictures, no proof}

The first example I would like to give is the exhibition named "Playing BAUHAUS" that was demonstrated in 2019 in the exhibit space of the Russian State Art Library (RSAL). It was the first show inside the "RSAL Studio" project, which is aimed to work with emerging artists - students of Moscow contemporary art schools and art colleges.

"Playing BAUHAUS" had a simple conception each participant chose herself (only female artists attended) a mentor from 100 years old BAUHAS and created an artwork which was a replica to the mentor's oeuvre and also demonstrated the student's artistic approach.

At some point it became obvious that the show is popular among youth not only in Moscow. Due to that it was decided to make a detailed documentation, which contained a 3d-panorama image and video interviews with the participants. It seemed enough at the moment.

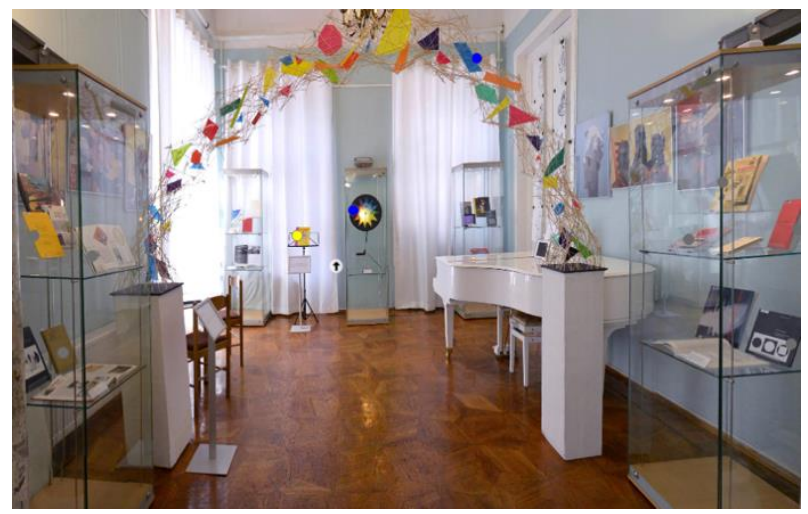

Figure 1: Playing BAUHAUS. Documentation view.

In some time, an event that affected the whole sphere had happened and cultural workers were forced to work from home. During that time, it became clear that the digital reconstruction the way it had been made was not enough. It gave a limited amount of information. So, in order to give the potential spectator a better understanding on how exhibition pieces were developed, young artists agreed to give their sketches and bibliography they used while doing the research. This way the digital documentation was not so flat, in a figure of speech. For artists it became a replica on a catalogue because it is very handy to have a URL (http://bauhausrgbi.tilda.ws/) to the project you participated in. 


\subsection{Low budget and digital}

While going deeper in the specifics of new cultural Zoom life if became obvious that all institutions need to demonstrate something. For those departments that work with video art it was easy. E.g. the Pushkin Museum of Fine Arts made a fantastic project named '100 Ways to Live a Minute' (https://100waystoliveaminute.pushkinmuseum.art/ ?lang=en) where they presented all important video artists in three sections, plus there were also screenings for limited time periods, which made the project more offline-like.

For RSAL one of the first fully digital projects was "VKhUTEMAS - XXI" (http://vkhutemas.tilda.ws/) which had the same mentor-student model as "Playing BAUHAUS", but unlike passed show, the new one was an online project.

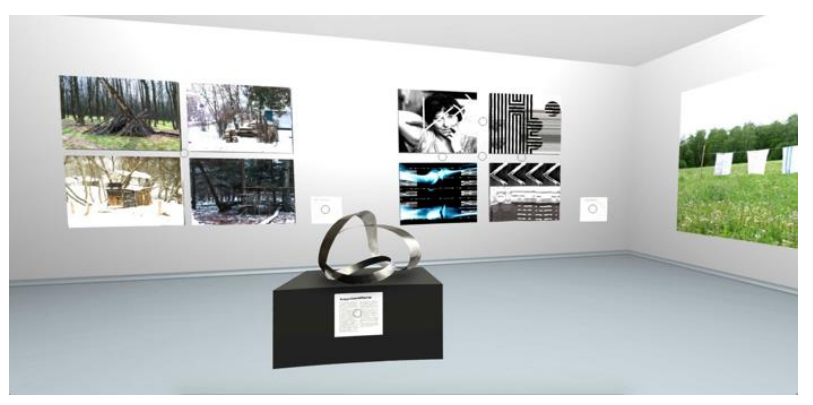

Figure 2: VKhUTEMAS - XXI. Viewing room.

It was a fast decision made in the first days of the lockdown. For young artists it came out to be an interesting challenge, because in the pre-pandemic life they knew that they had to visit the library and work with literature on the subject before choosing a mentor and creating their own piece. In fact, half of the works had a digital approach. Two digital zines, a digital series of book covers and an animated photo piece about the city.

It is of my opinion that this experience helped young artists to experiment with different art mediums because before it they have never tried to work with the new media.

Artists like Anastasiya Buoy, Shamil Shaaev, Masha Shprayzer and Katerina Ser'yoznaya created their pandemic show works on their computers unlike other artists who decided to make real objects and photograph them for the future exhibit.

Many of us will agree that it is quite tricky to fully engage with objects that were documented for online feed. As active spectators we demand the opportunity to walk around them if it is a sculpture, or be able to touch it when the artist claims that his/her piece is interactive. But if we keep in mind that the "VKhUTEMAS - XXI" was very low funded we will understand that the curator was in no position to demand only digital art works from the participants.

\subsection{Digital art in an educational opportunity}

As we follow the trends and tendencies of digital art online demonstration among young artists we are unable to notice one of the best, in my opinion, projects made in that sphere. It is an exhibition made by first year of study project-oriented MA program "-Da.Digital Art" and their exhibition "Expectation for the New Nature" (https://expo.dafefu.cc/en/).

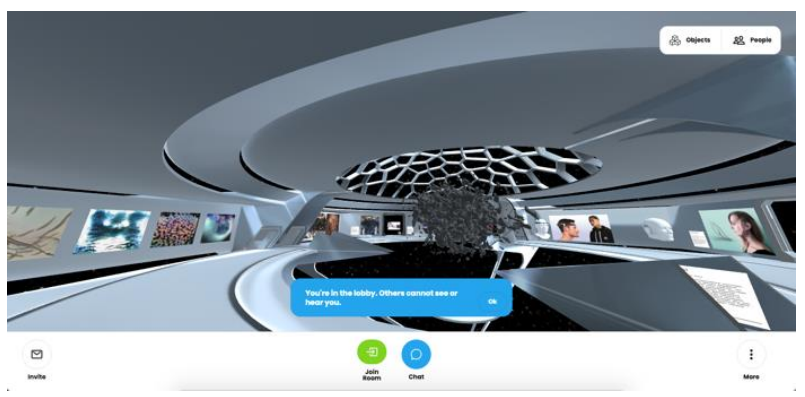

Figure 3: Expectation for the New Nature. General view.

First of all, it is fantastic that such MA program exists in Russia. The second notable moment is that the program is created by the Far Eastern State Technical University (Vladivostok, Russia) and not a Moscow based institution.

As soon as we follow the link we see that the organisers were kind enough to offer the potential spectator several options on how to watch the show: via smartphone, on a computer screen and with the help of VR.

While you scroll the main page you see the section that explains how to move in this digital space (keys are very similar to the gamer world ones). That gives us the atmosphere of a real visit to a gallery.

The designed space is futuristic, as if the spectator is entering a science fiction novel, where a group of people is cruising in outer space during their vacation.

What most catches the eye is the fact that the exhibit designers tried to overcome the abstractness of the spectator's category in the show by creating rooms. This way anyone who enters that digital space can chat with people during their visit. 


\section{CONCLUSION}

As it was said in the above, this text is a thought on a subject during the specific timeframe we are facing at the moment. It was important for the author to bring together three specific projects to highlight their strong and week sides. This way the reader will decide for him/herself what a contemporary digital art project should look like and how to work and curate in such sphere. Maybe the future digital artists and curators will solve the questions we have today.

\section{REFERENCES}

100 Ways to Live a Minute. Digital exhibition. https://100waystoliveaminute.pushkinmuseum.art/? lang=en (retrieved 15 March 2021).

Benjamin, W. (2007) The Work of Art in the Age of Mechanical Reproduction. In Benjamin, W.
Illuminations, Schockenbooks, New York. pp. 217252.

Böhme, G. (1993) Atmosphere as the Fundamental Concept of New Aesthetics. Thesis Eleven, Number 36, pp. 113-126.

Expectation for the New Nature. Digital exhibition. https://expo.dafefu.cc/en/ (retrieved 15 March 2021).

Playing BAUHAUS. Digital exhibition. http://bauhausrgbi.tilda.ws/_retrieved 15 March 2021).

Tavani, E. (2018) The Construction of Situations and Atmospheres in Installation Art. In Atmosphere/ Atmospheres. Testing a New Paradigm. MilanoUdine, Mimesis International, 2018. pp. 129-145.

VKhUTEMAS - XX. Digital exhibitionl. http://vkhutemas.tilda.ws/ (retrieved 15 March 2021) 